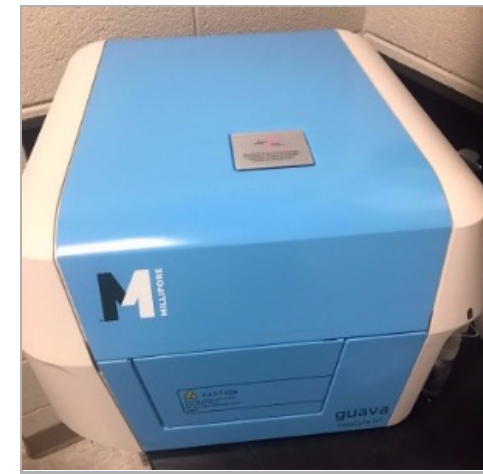

JUL 14, 2017

\section{open ठAccess}

DOI:

dx.doi.org/10.17504/protocol s.io.ikyccxw

Protocol Citation: Dr. Steven Wilhelm, Alyssa Alsante 2017. Guava Flow Cytometry. protocols.io https://dx.doi.org/10.17504/p rotocols.io.ikyccxw

License: This is an open access protocol distributed under the terms of the Creative Commons Attribution License, which permits unrestricted use, distribution, and reproduction in any medium, provided the original author and source are credited

Protocol status: Working

Created: Jun 29, 2017

Last Modified: Mar 21, 2018

PROTOCOL integer ID: 6520

\section{(3) Guava Flow Cytometry}

Dr. Steven Wilhelm, Alyssa Alsante

The Aquatic Microbial Ecology Research Group - AMERG (The Buchan, Zinser and Wilhelm labs)

Steven W Wilhelm

The University of Tennessee, Knoxville

\section{ABSTRACT}

Please contact Dr. Steven Wilhelm (wilhelm@utk.ed) for additional information regarding this protocol.

\title{
Cleaning the machine
}

1 Click CLEANING from the main menu 
Note

Always clean the machine before and after use

\section{Click START CLEAN}

3 Load the following:

* $\mathrm{dH}_{2} \mathrm{O}$ in $\mathrm{W} 1, \mathrm{~W} 2, \mathrm{~W} 3, \mathrm{~W} 4, \mathrm{~W} 5, \mathrm{~W} 6$, and position 1

*100 $\mu \mathrm{L}$ bleach in position 2

*GUAVA ICF in position 3 and 4

$* \mathrm{dH}_{2} \mathrm{O}$ in capillary shutdown (position 9)

\section{GUAVA InCyte Acquisition Workflow}

4 To ensure optimal performance, allow the machine to warm up for at least 10 min prior to acquiring samples.

5 Select InCyte from the main menu

6 Click the EDIT WORKLIST button

7 Define the worklist parameters (e.g., wells to analyze, events to acquire, time to acquire, dilution factor, original volume, replicates, etc)

8 Click RUN WORKLIST 
9 Select the folder where you want to save the data file and click SAVE

10 Select the Analysis Method that you want to use for your specific sample set. To open a saved method, click RETRIEVE on the dialog box, then OPEN.

Note

If you want to creat a new Analysis Method, click NEW, then OK and set the parameters.

11 Place the microtiter plate in the tray

12 Load the following cleaning solutions:

$* \mathrm{dH}_{2} \mathrm{O}$ in $\mathrm{W} 2, \mathrm{~W} 4, \mathrm{~W} 5$

*Empty tubes in W5, W6

*100 $\mu \mathrm{L}$ bleach in $\mathrm{W} 1$

*ICF in position 10

$\star \mathrm{dH}_{2} \mathrm{O}$ in position 9 (capillary shutdown)

13 Click OK to load

14 Select the sample for ADJUST SETTINGS in the dialog box

15 Select the type of plots and parameters you wish to display

16 Use the GAIN CONTROLS to select the Threshold parameter from the drop-down menu and use to adjust the gains (FSC, SSC, GRN, YLW, RED, NIR, RED2, or NIR2) 
17 To adjust COMPENSATION, click NEXT STEP, then ADJUST SETTINGS

18 When you are finished adjusting the settings, click NEXT STEP.

19 Click RESUME WORKLIST and it will begin acquiring samples 